\title{
The Effect of Inclusive Leadership on Employees' Procrastination
}

\author{
Han Lin \\ Jinan University, Guangzhou, China \\ Email: gy11lh@163.com
}

How to cite this paper: Lin, H. (2018). The Effect of Inclusive Leadership on Employees' Procrastination. Psychology, 9, 714-727. https://doi.org/10.4236/psych.2018.94045

Received: March 23, 2018

Accepted: April 17, 2018

Published: April 20, 2018

Copyright $\odot 2018$ by author and Scientific Research Publishing Inc. This work is licensed under the Creative Commons Attribution International License (CC BY 4.0).

http://creativecommons.org/licenses/by/4.0/

\begin{abstract}
Based on self-determination theory, our study investigates the mechanism and boundary condition of procrastination behavior. We had a sample of $327 \mathrm{em}$ ployees to test our hypothesis, and regression method and the structural equation model were used to analyze the data. The results show that: 1) inclusive leadership could negatively influence on procrastination behavior; 2) mediating effect of intrinsic motivation was found between inclusive leadership and procrastination; 3) moderating effects of perceived insider status were found upon the relationship between intrinsic motivation and procrastination behavior; 4) moreover, perceived insider status moderated the mediating effect of intrinsic motivation between inclusive leadership and procrastination behavior.
\end{abstract}

\section{Keywords}

Inclusive Leadership, Employees' Procrastination, Intrinsic Motivation, Perceived Insider Status, Self-Determination Theory

\section{Introduction}

The acceleration of social development pace and quick development of information technology is accompanied by more and more procrastination phenomenon. Procrastination refers to the voluntary delay of an intended action despite the expecting negative consequences for the act (Steel, 2007). Procrastination could not only influence the employees' performance, salary and well-being (Cadena, Schoar, Cristea, \& Delgado-Medrano, 2011), but also reduce the efficiency, and increase working cost to the organization (D'Abate \& Eddy, 2007). Thus, how to reduce employees' procrastination behavior draws more and more attention from the managerial field. However, current research mainly takes a student group as the study object, and employees' procrastination has received 
less attention. Klingsieck (2013), Sirois and Pychul (2016) have appealed that researcher should expand the range of procrastination in the workplace. In response to the appeal, our study will focus on the employee, and find the way to reduce procrastination.

Researcher has investigated the reasons which probably cause to procrastination, however, most of the previous researches have focused on employees' individual factor, such as individual's intrinsic motivation, task characteristic, workload and so on (Ackerman \& Gross, 2005; Brownlow \& Reasinger, 2000; DeArmond, Matthews, \& Bunk, 2014), but less on external factor such as leadership. As a part of the organization, employees' behavior should be influenced by their leader or organization. For example, leader could influence how employee uses time, and influence their performance (Mohammed \& Nadkarni, 2014). Leader could help the employee to perform better through supervision and support (Gevers \& Demerouti, 2013). Undoubtedly, leadership should be seriously considered to research employees' procrastination.

Besides, the impact of the external factor on procrastination remains controversial. On one hand, researchers considered that the relaxed working environment may induce employees' procrastination (Sirois \& Pychyl, 2016). On the other hand, there are some studies pointed out that employee could show more procrastination behavior under the strict management lacking of opportunity and autonomy (Meyer, Dalal, \& Bonaccio, 2009; Nguyen, Steel, \& Ferrari, 2013). In order to explore the relationship between the relaxed, autonomous environment and procrastination, we import inclusive leadership. As interactional leadership which leaders interact with follower, inclusive leadership was regarded as compatible leadership to adapt the complicated management context (Zhu \& Qian, 2014). Inclusive leadership could help to employees' active behavior. For example, inclusive leadership could facilitate employees' innovation behavior and work engagement (Carmeli, Reiter-Palmon, \& Ziv, 2010; Choi, Tran, \& Park, 2015). However, the role of inclusive leadership in employees' procrastination even deviant behavior is still unclear. So, we will discuss the role of leadership in procrastination behavior under the workplace environment.

Intrinsic motivation always plays an important role in the research on procrastination. It is essential to discuss procrastination through intrinsic motivation. Based on Self-Determination Theory, individual has three basic needs: competence, autonomy, relatedness. When the basic need was satisfied, individual's intrinsic motivation would be strengthened (Gagné \& Deci, 2005). As a relational leadership, inclusive leadership could show their openness, availability and accessibility in the interaction process with followers. So it may satisfy employees' basic need, and then improve their intrinsic motivation. Moreover, research has proved that people with high level intrinsic motivation could show less procrastination (Brownlow \& Reasinger, 2000; Klingsieck, 2013). Therefore, we proposed that intrinsic motivation could make an important influence between inclusive leadership and procrastination behavior. 
Moreover, it is also important to consider the content of culture values into the research under the Chinese cultural emphasizing collective consciousness and individual belongingness. In this context, whether employees' could perceive the sense of organizational belonging and identify to their "internal members", will also influence employees' behavior (Zhao \& Tang, 2015). Thus, our study will consider perceived insider status into the research. Perceived insider status refers to people's perception of their identity of "insider member" and of the degree of being accepted (Stamper \& Masterson, 2002). Stamper and Masterson (2002) have indicated that, employees' who has higher perceived insider status could have less productive deviant behavior. And Li and his colleague (2014) have found that perceived insider status could moderate the relationship between environmental factor and individual behavior. And we also consider perceived insider status as a moderation role in this research.

In the summary, the current study seeks to provide a nuanced understanding of the relationship between inclusive leadership and procrastination behavior by the mediating role of intrinsic motivation and moderated role of the perceived insider status. The contributions of current study not only make a deep understanding to leadership and procrastination behavior on theory, but also provide guidance in practice.

\section{Hypothesis}

\subsection{Inclusive Leadership and Procrastination}

Research has shown that, procrastination behavior could influence by some job characteristic, but also influenced by leader's characteristic (Metin et al., 2016; Schraw et al., 2007; Steel \& Klingsieck, 2016). For instance, Schraw et al. (2007) indicated that, as a leader of students, teacher will impact on students' procrastination. Specifically, if teacher couldn't show clear direction and provide sufficient information for students, then student will behave more protracted. Similarly, employee's procrastination may influenced by their leader.

Inclusive leadership always means positively interaction with employee. Inclusive leadership has three characteristics in the interaction: openness, availability and accessibility. Through this three characteristics, inclusive leadership could response to employee more positively and support to the employee more effectively (Carmeli et al., 2010), then reduce employee's negative behavior. Firstly, when leader show more openness, it will listen to employee's new viewpoint, focus on the way that could enhance employee's work efficiency, and discuss the way to achieve employee's goal with employee. Through openness, leader could help employee to be competent for the job, and reduce the procrastination for task difficulty. Secondly, it means that employee could consult to the leader anytime when leader shows the availability. Leader's availability could not only improve employee's ability, but also facilitate their participation of job and autonomy for job (Hollander, 2012). Blunt and Pychy (2000) point out that, the employee could procrastinate less when they are autonomous. Thirdly, leader's 
accessibility will encourage the employee to seek help to their leader, and it helps to build a high quality relationship between them. In this process, employee's need of belongingness will be satisfied (Komives et al., 2013; Randel et al., 2017).

According to Self-determination theory, people have three basic psychological need: competence, autonomy and relatedness, and people will strive for these need and tend to the environment that satisfied these need (Gagné \& Deci, 2005; Zhang et al., 2010). When the basic psychological need was satisfied, people showed more positive consequence, in contrast, it will bring the negative influence (Deci \& Ryan, 2000; Gagné \& Deci, 2005; Grund \& Fries, 2018). Katz et al (2014) have indicated that when individuals are in "need-supportive" environment which could support their need of competent, autonomy and relatedness, their procrastination behavior will reduce obvious. As an open, encouraging leadership style, inclusive leadership may provide the "need-supportive environment" to the employee, then let employee delay less.

Therefore, we propose the following hypothesis:

Hypothesis 1: Inclusive leadership is negatively related to procrastination behavior.

\subsection{The Mediating Role of Intrinsic Motivation}

Intrinsic motivation involves people doing an job because their interest and affection and derive spontaneous satisfaction from the job (Gagné \& Deci, 2005), it always derives from the positive response to the task or job, such as curiousness, involvement, interest, satisfaction and so on (Amabile et al., 1996; Van Yperen \& Hagedoorn, 2003). Some studies have manifested that leadership could influence to employee's intrinsic motivation. For instance, Shin and Zhou (2003) has found that transformational leadership could positively influence one's intrinsic motivation. Zhang and Bartol (2010) also indicated that empowering leadership could influence employee's intrinsic motivation through empowerment to employee.

As an open, encouraging and supportive leadership, inclusive leadership will facilitate the formation of positive response to the job. To be more specific, inclusive leadership's openness could encourage employees to express their opinions and to join the discussion more positively (Nembhard \& Edmondson, 2006; Carmeli et al., 2010). So, employee may prone to perceive the importance and significance of the work that they are engaged in, then promote their intrinsic motivation (Amabile et al., 1996). In the same vein, leader's availability will encourage the employee to consult with leader actively and make them more autonomy to work (Hollander, 2012). Moreover, leader's accessibility will bring more active interaction between leader and employee, in turn help to build the high quality relationship of them. Some research refers that high quality relationship could motivate the employee's interest and involvement in the job, and then promote their intrinsic motivation (Nishii \& Mayer, 2009). Besides, according to Self-determination theory, inclusive leadership could create a 
need-supported environment for the employee, then make them show more positive response for the job, and make them love the job. Thus, inclusive leadership could be positively influence on employee's intrinsic motivation.

As mentioned before, intrinsic motivation has been regarded as an important factor for procrastination (Rakes \& Dunn, 2010; Dunn, 2014). As the strength to engage in an activity (Brownlow \& Reainger, 2000), it reflected the degree that someone engages in work for activity itself. Some research has indicated that individual's work motivation could not only come from the work itself, but also some extrinsic factor such as money, achievement or supervision (Gagné \& Deci, 2005). However, once the extrinsic stimulation disappears, employee could keep their action no more. For example, when employee works hard for their leader's supervision, once there is no supervision, they may delay or procrastinate. Therefore, the motivation could be maintained better when employee's satisfaction is from the work itself but not the other extrinsic stimulation. Some research also manifest that people who have higher intrinsic motivation will procrastinate less (Dunn, 2014; Katz et al., 2014; Rakes \& Dunn, 2010; Senécal et al., 2003).

In sum, inclusive leadership may provide an environment that satisfied employee's basic psychological need, then improve their intrinsic motivation, in turn reduce their procrastination behavior. Hence, intrinsic motivation may play a mediating role between inclusive leadership and procrastination behavior.

Therefore, we propose the following hypothesis:

Hypothesis 2: Inclusive leadership is positively related to intrinsic motivation.

Hypothesis 3: Intrinsic motivation is negatively related to procrastination behavior.

Hypothesis 4: Intrinsic motivation mediated the like between inclusive leadership and procrastination behavior.

\subsection{The Moderating Role of Perceived Insider Status}

The extent to which employees perceive themselves to be organization insider is perceived insider status, that is the sense that employees have gained a "individual space" and be accepted by their work organization (Stamper \& Masterson, 2002). Perceived insider status is an important indicator to measure employees' self-concept and their belongingness to the organization (Chen \& Aryee, 2007; Masterson \& Stamper, 2003). Employees who have a high level of perceived insider status own more belongingness and identify to their organization, so that they will strive more for their organization and prone to show more positive attitude and behavior (Wang, Cai, \& Lin, 2014). Stamper and Masterson (2002) indicated that a high level of perceived insider status influence one's self-determination behavior, such as increase organizational citizenship behavior or decrease deviant behavior.

Actually, perceived insider status not only impact on employees directly, but also plays an important role between context factor and employees' behavior. Li 
et al. (2014) has shown that perceived insider status can moderate the risk of organizational policy, then facilitate employees' voice behavior. Choi et al. (2017) also indicated that perceived insider status could interaction with family-supportive management, then positively influence employees' organizational commitment and organizational citizenship behavior through improve their job satisfaction. Hence, the influence of inclusive leadership to employees' behavior possibly affected by perceived insider status.

In this regard, when employees consider themselves as a part of organization, they will have high identify with the organization (Stamper \& Masterson, 2002). This sense of identifies promote employees shows more helpful behavior in the organization. So, employees make no difference although they have different extent of intrinsic motivation, because high identify with organization impels them to avoid harm to the organization's interest. In contrast, for employees who have low level of perceived insider status, they always feel be excluded from their organization, so that they have low identify with the organization. Then, employees in low intrinsic motivation could be hard to engage in job, even behave harmful for organizational benefit, such like delay the task or job. Thus, when the level of perceived insider status is low, the negative relationship between intrinsic motivation and procrastination behavior will be strong.

To summarize, we hypothesize:

Hypothesis 5: Perceived insider status moderates the negative relationship between intrinsic motivation and procrastination behavior, such that this relationship is more strongly when the degree of perceived insider status is low than when the degree of perceived insider status is high.

Hypothesis 6: Perceived insider status moderates the mediating effect of intrinsic motivation on the negative relationship between inclusive leadership and procrastination behavior. That is, the stronger the perceived insider status is, the weaker the negative correlation between inclusive leadership and employee's procrastination which through intrinsic motivation is.

\section{Method}

\subsection{Participants and Procedure}

The sample included 327 employees working in different industries in China. There were 167 women and 159 men in the sample. Most of the participants within the age range of 21 to 30 , to $64.2 \%$, the average age was 29.99 years. And for $56.3 \%$ of participants are general staff, $25.1 \%$ of participants are junior managers, $15.3 \%$ are middle manager, and $3.4 \%$ are senior manager. Moreover, $21.1 \%$ of participants are engaged in service work, $19.9 \%$ of them are in managerial work, $17.7 \%$ are in marketing work and $14.1 \%$ are in research and development work.

\subsection{Measures}

Participants were required to answer an on-line questionnaire consisting of four 
different self-report measures on procrastination, perceived of their leader's leadership style, intrinsic motivation and perceived of insider status. The information of questionnaire is shown in next.

Procrastination

We used the Irrational Procrastination Scale (Steel, 2007) which is a 9-item questionnaire to measure the irrational tendency of an individual to procrastinate. Item was rated on a 5 -point Likert scale ( $1=$ strongly disagree) to $(5=$ strongly agree). A sample item is "When I should be doing one thing, I will do another". The Cronbach's $\alpha$ is 0.876 .

Inclusive Leadership

We assessed inclusive leadership using the 9-item scale of Carmeli, Reiter-Palmon and Ziv (2010), which including three dimensions: openness, availability and accessibility. It was scored on a 5-point Likert-type scale from 1 (strongly disagree) to 5 (strongly agree). A sample item is 'The manager is open to hearing new ideas'. The Cronbach's $\alpha$ is 0.937 .

Intrinsic motivation

We assessed intrinsic motivation using the 12-item adjusted version scale from Van Yperen and his associates, which were based on Vallerand and his associates (1997). This 12-item scale including three types of intrinsic motivation: to know, to accomplish things and to experience stimulation. It was scored on a 5-point Likert-type scale from 1 (strongly disagree) to 5 (strongly agree). A sample item is "Because I feel a lot of personal satisfaction while mastering certain difficult job skills". The Cronbach's $\alpha$ is 0.946 .

Perceived insider status

A 6-item scale developed by Stamper and Masterson (2002) was used to measure employees' perceived insider status. Response options ranged from $(1=$ strongly disagree) to ( $5=$ strongly agree). A sample item is "I feel very much a part of my work organization". The Cronbach's $\alpha$ is 0.898 .

\section{Result}

\subsection{Descriptive Analysis}

Table 1 shows the means, standard deviations and correlations of four constructs of our measurement model. The significant associations were observed between inclusive leadership and intrinsic motivation $(\mathrm{r}=0.486, p<0.01)$ and procrastination $(\mathrm{r}=-0.244, p<0.01)$, between intrinsic motivation and procrastination $(\mathrm{r}=-0.340, p<0.01)$, between perceived insider status and intrinsic motivation $(\mathrm{r}=0.420, p<0.01)$ and procrastination $(\mathrm{r}=-0.380, p<0.01)$.

\subsection{Confirmatory Factor Analysis}

To evaluate the validity of our variables, we conducted a confirmatory factor analyses (CFA) with Mplus 7.4. Specifically, we tested our measurement model by comparing our four-factor model (inclusive leadership, intrinsic motivation, perceived insider status, procrastination) with other rival model present in Table 2. 
Table 1. Means, standard deviations (SD), and correlations of variables $(\mathrm{N}=327)$.

\begin{tabular}{cccccccccc}
\hline & Gender & Age & Edu & WA & Position & IL & IM & PIS & PB \\
\hline Gender & 1.000 & & & & & & & & \\
Age & -0.071 & 1.000 & & & & & & & \\
Edu & 0.049 & $-0.238^{* *}$ & 1.000 & & & & & & \\
WA & $-0.127^{*}$ & $0.841^{* *}$ & $-0.356^{* *}$ & 1.000 & & & & & \\
Position & $-0.142^{*}$ & $0.554^{* *}$ & -0.047 & $0.586^{* *}$ & 1.000 & & & & \\
IL & $0.110^{*}$ & -0.077 & -0.051 & -0.059 & 0.003 & 1.000 & & & \\
IM & 0.101 & -0.080 & 0.040 & -0.057 & -0.010 & $0.486^{* *}$ & 1.000 & & \\
PIS & $0.112^{*}$ & -0.001 & -0.086 & -0.014 & -0.004 & $0.389^{* *}$ & $0.420^{* *}$ & 1.000 & \\
PB & -0.016 & -0.067 & 0.076 & -0.089 & -0.003 & $-0.244^{* *}$ & $-0.340^{* *}$ & $-0.380^{* *}$ & 1.000 \\
Mean & 1.510 & 2.470 & 2.560 & 2.530 & 1.660 & 3.531 & 3.691 & 3.525 & 2.478 \\
SD & 0.501 & 0.875 & 0.887 & 1.153 & 0.857 & 0.948 & 0.896 & 0.976 & 0.919 \\
\hline
\end{tabular}

Note: ${ }^{*} p<0.05,{ }^{* *} p<0.01$. Edu: Employees' education, $W A$ : working age, $I L$ : Inclusive Leadership, $I M:$ Intrinsic motivation, PIS: Perceived insider status, $P B$ : Procrastination behavior.

Table 2. Results of confirmatory factor analyses.

\begin{tabular}{cccccccc}
\hline Model & factor & $\chi^{2}$ & $d f$ & $\chi^{2} / d f$ & RMSEA & CFI & TLI \\
\hline Four-factor model & IL, IM, PIS, PB & 1182.770 & 514 & 2.301 & 0.063 & 0.914 & 0.906 \\
Three fator-1 model & IL, IM + PIS, PB & 2376.728 & 524 & 4.536 & 0.104 & 0.762 & 0.745 \\
Three fator-2 model & IL + PIS, IM, PB & 2399.059 & 524 & 4.578 & 0.105 & 0.759 & 0.742 \\
Three fator-3 model & IL + IM, PIS, PB & 2855.392 & 524 & 5.449 & 0.117 & 0.701 & 0.680 \\
Two factor model & IL + PIS, IM + PB & 3144.235 & 526 & 5.978 & 0.123 & 0.664 & 0.642 \\
One-factor model & IL + IM + PIS + PB & 4348.770 & 527 & 8.252 & 0.150 & 0.505 & 0.473 \\
\hline
\end{tabular}

$I L$ : Inclusive Leadership, IM: Intrinsic motivation, PIS: Perceived insider status, PB: Procrastination behavior. RMSEA: Root-mean-square error of approximation, CFI: Comparative fit index, TLI: Tucker-Lewis index.

And we use chi-squared, chi-squared/df, RMSEA, CFI, TLI to assess the model fit. The result indicated an acceptable model fit $\left(\chi^{2} / d f=2.301<3\right.$, RMSEA $=$ $0.063<0.08$, CFI $=0.914>0.90, \mathrm{TLI}=0.906>0.90$ ). As shown in Table 2 , the fit indexes revealed that the four-factor model fit the data considerably better that other alternative models. Therefore, the distinctiveness of the key variables was supported. Given these results, four constructs could be applied in further analysis.

\subsection{Test of Hypotheses}

To test our hypotheses, we conducted hierarchical regression analyses with SPSS 22.0. Hypothesis 1 predicted that Inclusive leadership is negatively associated with procrastination behavior. As showed in Table 3, inclusive leadership was negatively related to procrastination behavior $(\beta=-0.253, p<0.001$, M4). Thus, Hypothesis 1 was supported. 
Table 3. Results of regression analyses $(\mathrm{N}=327)$.

\begin{tabular}{|c|c|c|c|c|c|c|c|c|c|}
\hline \multirow{2}{*}{ Variables } & \multicolumn{2}{|c|}{ IM } & \multicolumn{7}{|c|}{$\mathrm{PB}$} \\
\hline & M1 & M2 & M3 & M4 & M5 & M6 & M7 & M8 & M9 \\
\hline Gender & 0.089 & 0.032 & -0.033 & -0.003 & -0.001 & 0.007 & 0.021 & 0.013 & 0.011 \\
\hline Age & -0.138 & -0.087 & 0.007 & -0.020 & -0.042 & -0.047 & -0.014 & -0.018 & -0.016 \\
\hline Education & 0.044 & 0.091 & 0.047 & 0.022 & 0.063 & 0.050 & 0.025 & 0.071 & 0.073 \\
\hline Marriage & 0.007 & 0.001 & -0.046 & -0.043 & -0.043 & -0.042 & -0.030 & -0.070 & -0.070 \\
\hline WA & 0.037 & 0.063 & -0.097 & -0.111 & -0.084 & -0.091 & -0.125 & -0.061 & -0.060 \\
\hline Position & 0.066 & 0.018 & 0.074 & 0.099 & 0.097 & 0.105 & 0.100 & 0.054 & 0.053 \\
\hline Work type & 0.091 & 0.097 & 0.042 & 0.038 & 0.074 & 0.068 & 0.062 & 0.071 & 0.072 \\
\hline IL & & $0.483^{* * *}$ & & $-0.253^{* * *}$ & & -0.105 & & & 0.023 \\
\hline IM & & & & & $-0.358^{* * *}$ & $\begin{array}{c}-0.307^{* *} \\
*\end{array}$ & $-0.238^{\star * *}$ & $-0.167^{\star \star}$ & $-0.175^{\star *}$ \\
\hline PIS & & & & & & & $-0.284^{* * *}$ & $-0.223^{* * *}$ & $-0.227^{* * *}$ \\
\hline $\mathrm{IM} \times$ PIS & & & & & & & & $0.339^{* * *}$ & $0.343^{* * *}$ \\
\hline$\Delta \mathrm{R}^{2}$ & 0.026 & 0.253 & 0.016 & 0.078 & 0.141 & 0.149 & 0.205 & 0.305 & 0.099 \\
\hline Adjusted $\mathrm{R}^{2}$ & 0.005 & 0.234 & -0.005 & 0.055 & 0.119 & 0.125 & 0.183 & 0.283 & 0.281 \\
\hline $\mathrm{F}$ & 1.238 & $13.429^{* * *}$ & 0.745 & $3.373^{* *}$ & $6.506^{* * *}$ & $6.158^{\star * *}$ & $9.092^{* * *}$ & $13.865^{* * *}$ & $12.585^{\star * *}$ \\
\hline
\end{tabular}

Note: ${ }^{*} p<0.05,{ }^{* *} p<0.01,{ }^{* *} p<0.001$. WA: Working age, $I L$ : Inclusive Leadership, $I M$ : Intrinsic motivation, $P I S$ : Perceived insider status, $P B$ : Procrastination behavior.

Hypothesis 2 - 4 predicted the mediation role of intrinsic motivation between inclusive leadership and procrastination behavior. The result in Table 3 demonstrates that inclusive leadership was positively related to intrinsic motivation $(\beta=$ $0.483, p<0.001, \mathrm{M} 2)$, supporting hypothesis 2 . In addition, intrinsic motivation was negatively related to procrastination behavior $(\beta=-0.358, p<0.001, \mathrm{M} 5)$, supporting hypothesis 3 . When intrinsic motivation was present, the relationship between inclusive leadership and procrastination became non-significant $(\beta=$ $-0.105, p>0.05, \mathrm{M} 6)$, and the intrinsic motivation was significant $(\beta=-0.307, p$ $<0.001$, M6). Thus, Hypothesis 4 received support. Intrinsic motivation mediates the relationship between inclusive leadership and procrastination behavior.

To further confirm the mediation role of employees' intrinsic motivation, we use Mplus 7.4 to compute bias-corrected confidence intervals following the advice of Preacher and Haye (2008). With 5000 bootstrapping replications, we found that the indirect effect for inclusive leadership $\rightarrow$ intrinsic motivation $\rightarrow$ procrastination behavior was -0.160 , with a $95 \%$ bias-corrected bootstrap CI of [-0.277, -0.077] (Table 4). This finding indicates that inclusive leadership was negatively and significantly related employees' procrastination behavior via intrinsic motivation, providing support for Hypothesis 4.

Hypothesis 5 predicted that perceived insider status moderates the relationship between intrinsic motivation and procrastination behavior. As shown in Table 3, the interaction between intrinsic motivation and perceived insider sta- 
tus was positively related to procrastination $(\beta=0.339, p<0.001, \mathrm{M} 8)$. Thus, Hypothesis 5 was supported. Meanwhile, we computed the slopes one standard deviation above and below the mean of the perceived insider status, then plotted the interactive effect, shown in Figure 1. Figure 1 indicated that the stronger the perceived insider status is, the weaker the negative correlation between intrinsic motivation and procrastination behavior is.

To test the moderated mediation in Hypothesis 6, it predicts that perceived insider status moderates the indirect effects of intrinsic motivation. We performed a moderated path analysis at different levels of intrinsic motivation $( \pm 1$ SD), bootstrapping 5000 samples to compute the bias-corrected CI (see Table 5). When perceived insider status at a high level, the indirect effect was 0.455 with a $95 \% \mathrm{CI}$ of $[0.300,0.652]$. And the indirect effect was 0.226 with a $95 \% \mathrm{CI}$ of $[0.136,0.342]$ when in low level of perceived insider status. The effect of the difference between the two conditions was 0.229 with a $95 \%$ CI of $[0.160,0.318]$, indicating that the moderating effect of perceived insider status on the indirect

Table 4. Result of bootstrapping of mediation.

\begin{tabular}{cccc}
\hline Path & Estimate & $2.5 \%$ LLCI & $97.5 \%$ ULCI \\
\hline IL $\rightarrow$ IM & 0.462 & 0.343 & 0.597 \\
IM $\rightarrow$ PB & -0.346 & -0.556 & -0.162 \\
$\mathrm{IL} \rightarrow \mathrm{IM} \rightarrow$ PB (indirect effect) & -0.160 & -0.277 & -0.077 \\
$\mathrm{IL} \rightarrow$ PB (direct effect) & -0.095 & -0.263 & 0.048 \\
Total effect & -0.255 & -0.414 & -0.108 \\
\hline
\end{tabular}

$I L$ : Inclusive Leadership, IM: Intrinsic motivation, $P I S$ : Perceived insider status, $P B$ Procrastination behavior.

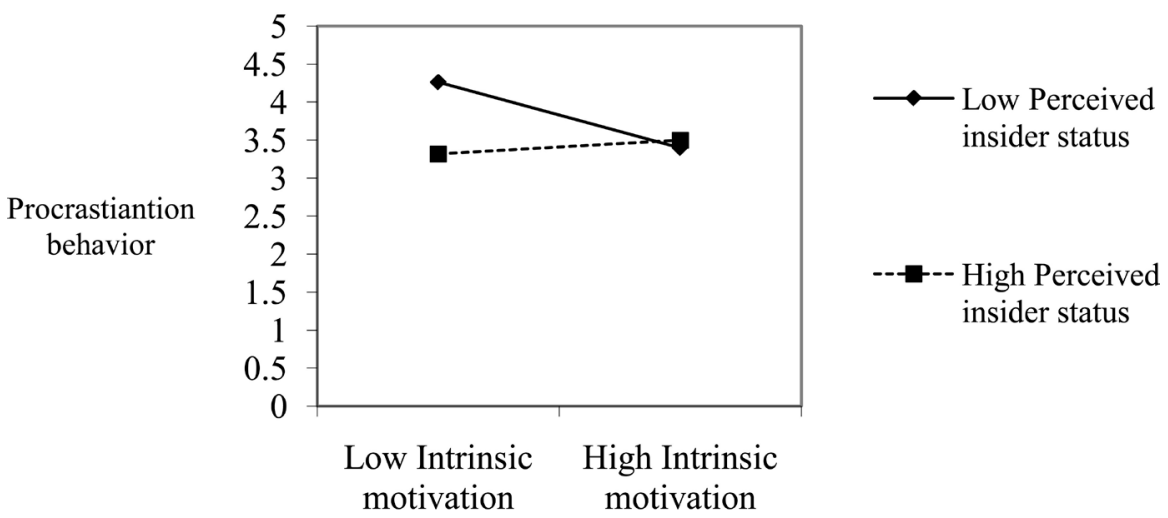

Figure 1. The moderating effect of perceive insider status.

Table 5. Results of bootstrapping of moderated mediation.

\begin{tabular}{cccc}
\hline & Estimate & $2.5 \%$ LLCI & 97.5\% ULCI \\
\hline High level perceived insider status (Mean + 1SD) & 0.455 & 0.300 & 0.652 \\
Low level perceived insider status (Mean - 1SD) & 0.226 & 0.136 & 0.342 \\
Difference & 0.229 & 0.160 & 0.318 \\
\hline
\end{tabular}


effect was significant, supporting Hypothesis 6.

\section{Discussion}

The purpose of this study was to investigate the procrastination behavior in the workplace context. More precisely, based on Self-Determination theory, we focus on the moderating role of perceived insider status and the mediating role of intrinsic motivation between inclusive leadership and procrastination. The results indicate that inclusive leadership negatively influences employees' procrastination behavior through employees' intrinsic motivation. That is, inclusive leadership could create a need-supportive environment which could satisfy employees' basic psychological need. According to Self-Determination theory, when the need was satisfied, employees' intrinsic motivation will be motivated and strengthened, so as to act more positive behavior and cut down negative behavior like procrastination (Gagné \& Deci, 2005). Finally, the results support the suggestion that perceived insider status as a moderator of this relationship. That is, the mediating effect will be different under different level of perceived insider status.

\subsection{Managerial Implication}

The managerial implication of our study focuses on following aspect. Firstly, improving employees' procrastination behavior not only is good for their physical and mental health, but also plays an immeasurable role in enhancing their work performance and promoting their career development. Secondly, according to our research conclusions, we encourage leaders to interaction with employees, so as to enhance the perceived of autonomy and relatedness by creating a need-supportive environment, and then motivate employees' passion for the job and reduce their procrastination behavior. Therefore, the research of the relationship between leadership and procrastination and the mechanism between them is of great significance to the management practice. Finally, as for the organization, the improvement of employees' behavior can not only improve the performance, but also help to build a positive image for the organization.

\subsection{Limitation and Future Research}

Although our study is helpful to broaden the research range, enrich related theories and guide the practice of procrastination behavior in China, there are still several limitations. At first, because we mainly conduct our survey in city of Guangdong province, the generalizability of the results may be limited. Thus, this type of survey should be repeated with participants from several areas in China even other countries. Second, our questionnaire is all self-reported by employees, so that it may result in common method variance inevitable to some extent. So the future research could broaden the source of investigation, and let the college or leader report the case jointly. Third, our study discusses the role of inclusive leadership in procrastination. However, different leadership could 
make diverse influence to employees' behavior. These indicate that future research could study procrastination of different leadership style, such as some rigorous, abusive leadership.

\section{References}

Ackerman, D. S., \& Gross, B. L. (2005). My Instructor Made Me Do It: Task Characteristics of Procrastination. Journal of Marketing Education, 27, 5-13. https://doi.org/10.1177/0273475304273842

Amabile, T. M., Conti, R., Coon, H., Lazenby, J., \& Herron, M. (1996). Assessing the Work Environment for Creativity. Academy of Management Journal, 39, 1154-1184. https://doi.org/10.2307/256995

Blunt, A. K., \& Pychyl, T. A. (2000). Task Aversiveness and Procrastination: A Multi-Dimensional Approach to Task Aversiveness across Stages of Personal Projects. Personality and Individual Differences, 28, 153-167. https://doi.org/10.1016/S0191-8869(99)00091-4

Brownlow, S., \& Reasinger, R. D. (2000). Putting off until Tomorrow What Is Better Done Today: Academic Procrastination as a Function of Motivation toward College Work. Journal of Social Behavior and Personality, 15, 15-34.

Cadena, X., Schoar, A., Cristea, A., \& Delgado-Medrano, H. M. (2011). Fighting Procrastination in the Workplace: An Experiment (No. w16944). Colombia: National Bureau of Economic Research. https://doi.org/10.3386/w16944

Carmeli, A., Reiter-Palmon, R., \& Ziv, E. (2010). Inclusive Leadership and Employee Involvement in Creative Tasks in the Workplace: The Mediating Role of Psychological Safety. Creativity Research Journal, 22, 250-260.

https://doi.org/10.1080/10400419.2010.504654

Chen, Z. X., \& Aryee, S. (2007). Delegation and Employee Work Outcomes: An Examination of the Cultural Context of Mediating Processes in China. Academy of Management Journal, 50, 226-238. https://doi.org/10.5465/AMJ.2007.24162389

Choi, J., Kim, A., Han, K., Ryu, S., Park, J. G., \& Kwon, B. (2017). Antecedents and Consequences of Satisfaction with Work-Family Balance: A Moderating Role of Perceived Insider Status. Journal of Organizational Behavior, 39, 1-11. (In Press)

https://doi.org/10.1002/job.2205

Choi, S. B., Tran, T. B. H., \& Park, B. I. (2015). Inclusive Leadership and Work Engagement: Mediating Roles of Affective Organizational Commitment and Creativity. Social Behavior and Personality: an International Journal, 43, 931-943. https://doi.org/10.2224/sbp.2015.43.6.931

D’Abate, C. P., \& Eddy, E. R. (2007). Engaging in Personal Business on the Job: Extending the Presenteeism Construct. Human Resource Development Quarterly, 18, 361-383. https://doi.org/10.1002/hrdq.1209

DeArmond, S., Matthews, R. A., \& Bunk, J. (2014). Workload and Procrastination: The Roles of Psychological Detachment and Fatigue. International Journal of Stress Management, 21, 137-161. https://doi.org/10.1037/a0034893

Deci, E. L., \& Ryan, R. M. (2000). The "What" and "Why" of Goal Pursuits: Human Needs and the Self-Determination of Behavior. Psychological Inquiry, 11, 227-268. https://doi.org/10.1207/S15327965PLI1104_01

Dunn, K. (2014). Why Wait? The Influence of Academic Self-Regulation, Intrinsic Motivation, and Statistics Anxiety on Procrastination in Online Statistics. Innovative Higher Education, 39, 33-44. https://doi.org/10.1007/s10755-013-9256-1 
Gagné, M., \& Deci, E. L. (2005). Self-Determination Theory and Work Motivation. Journal of Organizational behavior, 26, 331-362. https://doi.org/10.1002/job.322

Gevers, J. M., \& Demerouti, E. (2013). How Supervisors' Reminders Relate to Subordinates' Absorption and Creativity. Journal of Managerial Psychology, 28, 677-698. https://doi.org/10.1108/JPM-09-2011-0055

Grund, A., \& Fries, S. (2018). Understanding Procrastination: A Motivational Approach. Personality and Individual Differences, 121, 120-130. https://doi.org/10.1016/j.paid.2017.09.035

Hollander, E. (2012). Inclusive Leadership: The Essential Leader-Follower Relationship. Abingdon-on-Thames: Routledge.

Katz, I., Eilot, K., \& Nevo, N. (2014). "I'll Do It Later": Type of Motivation, Self-Efficacy and Homework Procrastination. Motivation and Emotion, 38, 111-119. https://doi.org/10.1007/s11031-013-9366-1

Klingsieck, K. B. (2013). Procrastination: When Good Things Don't Come to Those Who Wait. European Psychologist, 18, 24-34. https://doi.org/10.1027/1016-9040/a000138

Komives, S. R., Lucas, N., \& McMahon, T. R. (2013). Exploring Leadership: Facilitation and Activity Guide. San Francisco CA: Jossey-Bass Publishers.

Li, J., Wu, L. Z., Liu, D., Kwan, H. K., \& Liu, J. (2014). Insiders Maintain Voice: A Psychological Safety Model of Organizational Politics. Asia Pacific Journal of Management, 31, 853-874. https://doi.org/10.1007/s10490-013-9371-7

Masterson, S. S., \& Stamper, C. L. (2003). Perceived Organizational Membership: An Aggregate Framework Representing the Employee-Organization Relationship. Journal of Organizational Behavior, 24, 473-490. https://doi.org/10.1002/job.203

Metin, U. B., Taris, T. W., \& Peeters, M. C. (2016). Measuring Procrastination at Work and Its Associated Workplace Aspects. Personality and Individual Differences, 101, 254-263. https://doi.org/10.1016/j.paid.2016.06.006

Meyer, R. D., Dalal, R. S., \& Bonaccio, S. (2009). A Meta-Analytic Investigation into the Moderating Effects of Situational Strength on the Conscientiousness-Performance Relationship. Journal of Organizational Behavior, 30, 1077-1102.

https://doi.org/10.1002/job.602

Mohammed, S., \& Nadkarni, S. (2014). Are We All on the Same Temporal Page? The Moderating Effects of Temporal Team Cognition on the Polychronicity Diversity-Team Performance Relationship. Journal of Applied Psychology, 99, 404-422. https://doi.org/10.1037/a0035640

Nembhard, I. M., \& Edmondson, A. C. (2006). Making It Safe: The Effects of Leader Inclusiveness and Professional Status on Psychological Safety and Improvement Efforts in Health Care Teams. Journal of Organizational Behavior, 27, 941-966. https://doi.org/10.1002/job.413

Nguyen, B., Steel, P., \& Ferrari, J. R. (2013). Procrastination's Impact in the Workplace and the Workplace's Impact on Procrastination. International Journal of Selection and Assessment, 21, 388-399. https://doi.org/10.1111/ijsa.12048

Nishii, L. H., \& Mayer, D. M. (2009). Do Inclusive Leaders Help to Reduce Turnover in Diverse Groups? The Moderating Role of Leader-Member Exchange in the Diversity to Turnover Relationship. Journal of Applied Psychology, 94, 1412-1426. https://doi.org/10.1037/a0017190

Preacher, K. J., \& Hayes, A. F. (2008). Asymptotic and Resampling Strategies for Assessing and Comparing Indirect Effects in Multiple Mediator Models. Behavior Research Methods, 40, 879-891. https://doi.org/10.3758/BRM.40.3.879 
Rakes, G. C., \& Dunn, K. E. (2010). The Impact of Online Graduate Students' Motivation and Self-Regulation on Academic Procrastination. Journal of Interactive Online Learning, 9, 78-93.

Randel, A. E., Galvin, B. M., Shore, L. M., Ehrhart, K. H., Chung, B. G., Dean, M. A., \& Kedharnath, U. (2017). Inclusive Leadership: Realizing Positive Outcomes through Belongingness and Being Valued for Uniqueness. Human Resource Management Review, 28, 190-203. https://doi.org/10.1016/j.hrmr.2017.07.002

Schraw, G., Wadkins, T., \& Olafson, L. (2007). Doing the Things We Do: A Grounded Theory of Academic Procrastination. Journal of Educational Psychology, 99, 12-25. https://doi.org/10.1037/0022-0663.99.1.12

Senécal, C., Julien, E., \& Guay, F. (2003). Role Conflict and Academic Procrastination: A Self-Determination Perspective. European Journal of Social Psychology, 33, 135-145. https://doi.org/10.1002/ejsp.144

Shin, S. J., \& Zhou, J. (2003). Transformational Leadership, Conservation, and Creativity: Evidence from Korea. Academy of management Journal, 46, 703-714. https://doi.org/10.2307/30040662

Sirois, F. M., \& Pychyl, T. A. (2016). Procrastination, Health, and Well-Being. Cambridge, MA: Academic Press.

Stamper, C. L., \& Masterson, S. S. (2002). Insider or Outsider? How Employee Perceptions of Insider Status Affect Their Work Behavior. Journal of Organizational Behavior, 23, 875-894. https://doi.org/10.1002/job.175

Steel, P. (2007). The Nature of Procrastination: A Meta-Analytic and Theoretical Review of Quintessential Self-Regulatory Failure. Psychological Bulletin, 133, 65-94. https://doi.org/10.1037/0033-2909.133.1.65

Steel, P., \& Klingsieck, K. B. (2016). Academic Procrastination: Psychological Antecedents Revisited. Australian Psychologist, 51, 36-46. https://doi.org/10.1111/ap.12173

Van Yperen, N. W., \& Hagedoorn, M. (2003). Do High Job Demands Increase Intrinsic Motivation or Fatigue or Both? The Role of Job Control and Job Social Support. Academy of Management Journal, 46, 339-348. https://doi.org/10.2307/30040627

Wang, Y. F., Cai, R. Y., \& Lin, X. C. (2014). The Relationship between Perceived Insider Status and Employee's Innovative Behavior: A Study of a Moderated Mediating Model. Foreign Economics \& Management, 36, 40-53.

Zhang, J., Zhang, J. B., Li, Y., \& Edward, L. D. (2010). An Effective Path for Promoting Work Motivation: The Self-Determination Theory Perspective. Advances in Psychological Science, 18, 752-759.

Zhang, X., \& Bartol, K. M. (2010). Linking Empowering Leadership and Employee Creativity: The Influence of Psychological Empowerment, Intrinsic Motivation, and Creative Process Engagement. Academy of Management Journal, 53, 107-128. https://doi.org/10.5465/AMJ.2010.48037118

Zhao, H. D., \& Tang, X. P. (2015). A Literature Review of Perceived Insider Status. Foreign Economics \& Management, 37, 56-65.

Zhu, Y., \& Qian, S. T. (2014). Analysis of the Frontier of Inclusive Leadership Research and Future Prospects. Foreign Economics \& Management, 36, 55-64. 